\title{
Revista de Enfermagem \\ UFPE On Line
}

Rev enferm UFPE on line. 2021;15:e244683

DOI: $10.5205 / 1981-8963.2021 .244683$

https: //periodicos.ufpe.br/revist as/revistaenfermagem

\section{ARTIGO ORIGINAL}

\section{EDUCAÇÃO AMBIENTAL E ARBOVIROSES NO CONTEXTO ESCOLAR \\ ENVIRONMENTAL EDUCATION AND ARBOVIROSES IN THE SCHOOL CONTEXT EDUCACIÓN AMBIENTAL Y ARBOVIROSIS EN EL CONTEXTO ESCOLAR}

Cícera Viviane Pereira ${ }^{1}$, Sabrina Alaide Amorim Alves ${ }^{2}{ }^{\oplus}$, Cicera Luciana da Silva Sobreira ${ }^{\circledR}$, Maria do Socorro Vieira Lopes ${ }^{4}$.

\section{RESUMO}

Objetivo: analisar as práticas pedagógicas voltadas à educação ambiental com a temática das arboviroses no contexto escolar. Método: trata-se de um estudo qualitativo, descritivo, realizado em escolas do Ensino Fundamental. Informa-se que fizeram parte do estudo 23 participantes. Utilizou-se, para a coleta de dados, uma entrevista semiestruturada. Analisaram-se os dados pelo software IRAMUTEQ e, para as análises dos conteúdos textuais, foram utilizadas as técnicas de Classificação Hierárquica Descendente. Resultados: dividiram-se os achados em cinco classes que apresentaram as principais facilidades e fragilidades encontradas para a realização de atividades relacionadas às arboviroses, caracterização das ações, planejamento e parcerias envolvidas nessas atividades e, por fim, apresentação das principais temáticas desenvolvidas nas escolas sobre educação ambiental. Conclusão: percebe-se a importância da inserção da temática saúde ambiental no contexto escolar, proporcionando, ao discente, a identificação de práticas voltadas para a prevenção de arboviroses.

Descritores: Saúde Ambiental; Infecções por Arbovirus; Instituições Acadêmicas, Promoção da Saúde; Educação Continuada; Educação em Saúde.

\section{ABSTRACT}

Objective: to analyze the pedagogical practices directed to environmental education with the subject of arboviroses in the school context. Method: it is a qualitative, descriptive study, carried out in elementary schools. It is informed that 23 participants took part in the study. A semistructured interview was used for data collection. The data were analyzed by IRAMUTEQ software and for the analysis of the textual contents the techniques of Descending Hierarchical Classification were used. Results: The findings were divided into five classes that presented the main ease and fragilities found for activities related to arboviroses, characterization of actions, planning and partnerships involved in these activities and, finally, presentation of the main themes developed in schools on environmental education. Conclusion: the importance of inserting the environmental 
health theme in the school context is perceived, providing the student with the identification of practices aimed at the prevention of arboviroses.

Descriptors: Environmental Health; Arbovirus Infections; Academic Institutions, Health Promotion; Continuing Education; Health Education.

\section{RESUMEN}

Objetivo: analizar las prácticas pedagógicas enfocadas en la educación ambiental con la temática de las arbovirosis en el contexto escolar. Método: se trata de un estudio cualitativo, descriptivo, realizado en escuelas primarias. Se informa que participaron 23 participantes en el estudio. Para la recolección de datos se utilizó una entrevista semiestructurada. Los datos se analizaron mediante el software IRAMUTEQ y, para el análisis de los contenidos textuales, se utilizaron las técnicas de Clasificación Jerárquica Descendente. Resultados: los hallazgos se dividieron en cinco clases que presentaron las principales facilidades y debilidades encontradas para la realización de actividades relacionadas con arbovirosis, caracterización de las acciones, planificación y alianzas involucradas en estas actividades $\mathrm{y}$, finalmente, presentación de los principales temas desarrollados en las escuelas sobre educación ambiental. Conclusión: se percibe la importancia de insertar el tema de la salud ambiental en el contexto escolar, proporcionando al estudiante la identificación de prácticas orientadas a la prevención de arbovirusis.

Descriptores: Salud Ambiental; Infecciones por Arbovirus; Instituciones Académicas; Promoción de la Salud; Educación Continua; Educación en Salud.

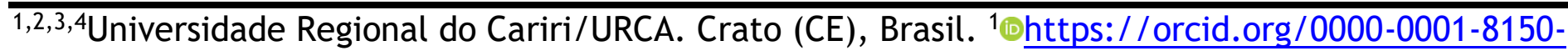

90762 2๑https://orcid.org/0000-0001-5831-4668 3 3๑https: //orcid.org/0000-0003-2380-9606

\section{3๑https: / / orcid.org/0000-0003-1335-5487}

*Artigo extraído da monografia, intitulado: Educação ambiental e arboviroses no contexto escolar. Universidade Regional do Cariri/URCA, 2018.

\section{Como citar este artigo}

Pereira CV, Alves SAA, Sobreira CLS, Lopes MSV. Educação ambiental e arboviroses no contexto escolar. Rev enferm UFPE on line. 2021;15:e244683 DOI: https://doi.org/10.5205/1981-8963.2021.244683 


\section{INTRODUÇÃO}

Dispersam-se as arboviroses por todo o planeta, contudo, elas apresentam diferentes taxas de casos confirmados. Encontra-se, no Brasil, um panorama de epidemias de dengue, zika e chikungunya. Explica-se que elas se caracterizam pela presença de um arbovírus transmitido por artrópodes como mosquitos, moscas e carrapatos e sua veiculação ocorre principalmente pela picada do mosquito Aedes aegypti, apresentando maior proliferação em épocas de verão, pois favorece a eclosão de ovos, devido ao calor e à chuva presentes nesse período. ${ }^{1}$

Sabe-se que dengue, zika e chikungunya são doenças emergentes e de notificação compulsória que constituem um problema de saúde pública no Brasil. Alerta-se que os números de casos suspeitos são preocupantes, pois, só em 2017, até a semana 51, foram registrados 250.853 casos prováveis de dengue, 185.550 casos prováveis de febre chikungunya e cerca de 17.339 casos prováveis de febre por zika. ${ }^{2}$

Acredita-se que a realização de aulas práticas e metodologias alternativas nas escolas são estratégias que conseguem contribuir positivamente para o processo de ensino-aprendizagem do discente, resultando em ações de conscientização e sensibilização do controle da proliferação do mosquito Aedes aegypti. ${ }^{3}$

Destaca-se a importância da participação da população, apesar da existência de políticas públicas e protocolos voltados para o enfrentamento das arboviroses.

Afirmou-se, em estudo, que não basta apenas existir políticas públicas e protocolos de enfrentamento para arboviroses, visto que a população também possui um papel fundamental no enfrentamento ao vetor. Torna-se necessário que ela entenda a totalidade dos problemas existentes em torno dessas patologias para que, assim, possa ajudar no controle dessas epidemias. ${ }^{4}$

Faz-se necessário, frente a essa problemática, investir em práticas de promoção da saúde e de prevenção, destacando a educação ambiental como uma estratégia para o enfrentamento e prevenção dessas arboviroses, já que a incidência de casos decorre de comportamentos e hábitos inadequados da sociedade atrelados às condições ambientais desfavoráveis, como a falta de saneamento básico. Constroem-se, em educação em saúde, os princípios de uma sociedade sustentável, potencializando mudanças culturais e sociais que favoreçam a melhoria socioambiental e, para o seu desenvolvimento, podem-se empregar estratégias de cuidado como promoção da saúde, prevenção e controle das doenças. ${ }^{5-6}$

Destaca-se o ambiente escolar como um espaço aberto às discussões de temas atuais como arboviroses, onde se pode inserir a educação em saúde como estratégia para facilitar o processo de 
aprendizagem em busca de alcançar prevenção e controle das doenças. Afirmou-se, em estudo como o de Santos, ${ }^{7}$ que os alunos possuem um conhecimento sobre dengue, zika e chikungunya por causa dos meios de comunicação, porém, esse entendimento é superficial, não sendo o bastante para a conscientização dos mesmos.

Acredita-se, diante do exposto, que as escolas parecem ser ambientes propícios para o desenvolvimento de ações de educação ambiental com crianças e adolescentes, tendo em vista que o conhecimento adquirido pode levar estes jovens a serem multiplicadores.

\section{OBJETIVO}

Analisar as práticas pedagógicas voltadas à educação ambiental com a temática das arboviroses no contexto escolar.

\section{MÉTODO}

Trata-se de um estudo descritivo, com abordagem qualitativa. Detalha-se que a pesquisa ocorreu no período de julho a novembro de 2018, no município de Farias Brito, cidade brasileira localizada na região Nordeste, no interior do Estado do Ceará. Elencaram-se como cenários da pesquisa escolas de Ensino Fundamental da zona urbana da cidade. Informa-se que o referido município possui apenas três escolas de Ensino Fundamental na zona urbana, a saber: Maria Carmosina Pinheiro Rodrigues; Antônio Paes de Andrade e Santa Bárbara, e todas participaram do estudo.

Constituiu-se a amostra por três coordenadores pedagógicos e vinte professores responsáveis pelo desenvolvimento de atividades de educação ambiental e arboviroses nas escolas de Ensino Fundamental do município de Farias Brito. Elegeram-se como critérios de inclusão: envolvimento no planejamento e/ou realização de práticas educativas sobre arboviroses nas escolas; ser coordenador pedagógico e/ou professor da escola há, pelo menos, seis meses.

Levantaram-se como critérios de exclusão: profissionais de educação que estejam de licença ou afastados no momento da coleta de dados e escolas que não realizam atividades voltadas para a temática em estudo. Acrescenta-se que as referidas escolas contavam, no total, com 79 professores, porém, apenas 23 professores adequavam-se aos critérios.

Utilizou-se uma entrevista guiada por um roteiro. Entrevistaram-se, inicialmente, os coordenadores pedagógicos de cada escola, que, no momento da entrevista, indicavam os professores responsáveis pelo desenvolvimento de atividades voltadas para a educação ambiental e arboviroses; em seguida, a pesquisadora entrava em contato com os professores, convidando-os a 
participarem da pesquisa e, após o aceite, marcava a entrevista conforme os horários disponíveis dos professores.

Utilizou-se, para a organização e análise dos dados, o software IRAMUTEQ (Interface de $R$ pour les Analyses Multidimensionnelles de Textes et de Questionnaires). Trata-se de um programa livre que se ancora no software $\mathrm{R}$ e que tem por função a realização de análises textuais e estatísticas sobre os corpus textuais e sobre tabelas de indivíduos por palavras, variando de análises simples até multivariadas, organizando o vocabulário de forma facilmente compreensível e visualmente clara. ${ }^{8}$

Constituiu-se o corpus textual pelas 23 entrevistas, que foram agrupadas em um único arquivo de texto no programa Libre Office, versão 5.4, sendo que, para a organização do corpus, foram feitas a leitura e as correções para a adaptação no software.

Utilizou-se, para análises dos conteúdos textuais, a técnica de Classificação Hierárquica Descendente (CHD), na qual os textos foram classificados em função de seus respectivos vocabulários, e o conjunto deles divide-se pela frequência das formas reduzidas.

Apresentaram-se os resultados da análise do software em forma de dendograma. Realizaram-se, em seguida, a interpretação e a síntese dos resultados por meio de uma leitura minuciosa.

Obedeceram-se, pela pesquisa, às exigências éticas e científicas para pesquisas envolvendo seres humanos, definidas na Resolução n. ${ }^{\circ}$ 466/12 do Conselho Nacional de Saúde/Ministério da Saúde, tendo sido aprovada por Comitê de Ética em Pesquisa da Universidade Regional do Cariri sob o parecer consubstanciado de número 2.844.517 / 2018.

\section{RESULTADOS}

Procederam-se, para a realização da análise dos dados, à preparação e à codificação do texto inicial, que se constituem em transcrever as entrevistas em um conjunto de textos denominada de corpus de análise, onde as perguntas foram suprimidas, mantendo-se somente as respostas em forma de um único texto. Constituiu-se, assim, o corpus textual por 23 textos organizados em um único arquivo, que originou $23 \mathrm{UCl}$ (Unidade de Contexto Inicial).

Analisou-se o arquivo pelo Iramuteq, após a transcrição realizada utilizando-se no Libreoffice writer do pacote libreoffice.org, sendo realizada a análise Classificação Hierárquica Descendente (CHD).

\section{Classificação Hierárquica Descendente}

Apresentam-se, na figura 1, as principais características da análise a serem consideradas após o processamento do corpus textual no Iramuteq. Percebe-se, diante deste, que a análise realizada pelo software dividiu o corpus em 142 segmentos de texto, onde, destes, se apresentou uma 
retenção de 108 segmentos para a construção das classes, o equivalente a 76\% de aproveitamento de análise.

\begin{tabular}{|lc|}
\hline Número de textos & 23 \\
Número de segmentos de texto & 142 \\
Número de formas distintas & 708 \\
Número de ocorrências & 5063 \\
Frequência média das formas por segmento & 220.13 \\
Número de classes & 5 \\
Retenção de segmentos de texto & 108 em 142 (76\%) \\
\hline
\end{tabular}

Figura 1. Informações da análise do IRAMUTEC. Crato (CE), Brasil, 2018.

Dividiu-se o corpus, na CHD, pelo Iramuteq, em cinco classes apresentadas em um dendograma (Figura 2), figura que, além de apresentar as classes, evidencia a ligação e a associação existentes entre elas. Formam-se as classes por segmentos de texto que apresentam vocabulário semelhante entre si e que são diferentes, mesmo apresentando semelhanças, do vocabulário de outras classes. ${ }^{8}$

Buscou-se, diante disso, identificar e interpretar nas mesmas seus domínios textuais, nomeandoas.

\begin{tabular}{|c|c|c|c|c|}
\hline Classe 2 & Classe 5 & Classe 3 & Classe 4 & Classe 1 \\
\hline $19.4 \%$ & $14,8 \%$ & $23.1 \%$ & $23.1 \%$ & $19.4 \%$ \\
\hline $\begin{array}{l}\text { cartaz } \\
\text { culminância } \\
\text { paródia } \\
\text { apresentar } \\
\text { dia } \\
\text { apresentação } \\
\text { projeto } \\
\text { organizar } \\
\text { peça } \\
\text { mosquito } \\
\text { panfleto } \\
\text { confeccionamos } \\
\text { sala } \\
\text { vídeo } \\
\text { ficar } \\
\text { texto } \\
\text { leitura } \\
\text { dar } \\
\text { relação } \\
\text { palestra } \\
\text { trazer } \\
\text { mandar } \\
\text { também } \\
\text { internet } \\
\text { aula } \\
\text { asarboviroses } \\
\text { retirar }\end{array}$ & $\begin{array}{l}\text { saúde } \\
\text { secretária } \\
\text { comunitário } \\
\text { agente } \\
\text { enfermeiro } \\
\text { ação } \\
\text { parceria } \\
\text { levar } \\
\text { oficina } \\
\text { educação } \\
\text { secretaria } \\
\text { planejamento } \\
\text { geralmente } \\
\text { como } \\
\text { social } \\
\text { endemia } \\
\text { reunião } \\
\text { vez } \\
\text { retirar } \\
\text { folheto } \\
\text { pse } \\
\text { dar } \\
\text { vir } \\
\text { até } \\
\text { participar } \\
\text { internet }\end{array}$ & $\begin{array}{l}\text { área } \\
\text { chicungunya } \\
\text { junto } \\
\text { dengue } \\
\text { reunir } \\
\text { zika } \\
\text { sentar } \\
\text { gestão } \\
\text { planejar } \\
\text { sala } \\
\text { mais } \\
\text { depois } \\
\text { professor } \\
\text { assunto } \\
\text { ciência } \\
\text { passado } \\
\text { então } \\
\text { ano } \\
\text { acordo } \\
\text { desenvolvido } \\
\text { multimeios } \\
\text { abordar } \\
\text { aqui } \\
\text { desenvolver }\end{array}$ & $\begin{array}{l}\text { ambiente } \\
\text { meio } \\
\text { preservação } \\
\text { lixo } \\
\text { limpo } \\
\text { ambiental } \\
\text { relacionado } \\
\text { semana } \\
\text { manter } \\
\text { gincana } \\
\text { livro } \\
\text { jogar } \\
\text { cuidado } \\
\text { escolar } \\
\text { através } \\
\text { comunidade } \\
\text { conversa } \\
\text { descarte } \\
\text { trabalhar } \\
\text { relação } \\
\text { falar } \\
\text { menino } \\
\text { importância } \\
\text { questão } \\
\text { ao } \\
\text { roda } \\
\text { parede }\end{array}$ & $\begin{array}{l}\text { facilidade } \\
\text { dificuldade } \\
\text { capacitação } \\
\text { não } \\
\text { específico } \\
\text { pai } \\
\text { conseguir } \\
\text { já } \\
\text { mundo } \\
\text { fragilidade } \\
\text { conhecido } \\
\text { muito } \\
\text { acesso } \\
\text { aluno } \\
\text { material } \\
\text { participar } \\
\text { envolver } \\
\text { temática } \\
\text { só } \\
\text { informação } \\
\text { grande } \\
\text { diferente } \\
\text { conscientizar } \\
\text { conhecimento } \\
\text { apoio } \\
\text { problema } \\
\text { professor } \\
\text { quando }\end{array}$ \\
\hline
\end{tabular}

Figura 2. As relações interclasses onde a leitura deve ser feita de cima para baixo, ou seja, em um primeiro momento, o corpus foi dividido em um subgrupo da qual resultou a classe 1 . Pontua-se 
que, em um segundo momento, a classe 1 deu origem a dois novos subgrupos, que se subdividiram, originando, em um primeiro momento, as classes 2 e 5 e, em um segundo momento, as classes 3 e 4, o que pressupõe que as classes 2 e 5 possuem uma maior relação de proximidade em relação às classes 3 e 4 e vice-versa, bem como que a classe 1, mesmo apresentando vocabulários semelhantes com as demais classes, é a que mais se distancia do conteúdo abordado pelas outras no que se relaciona a questões lexicais e às Unidades de Contexto Elementar (UCE) ou segmentos de texto que compõem a classe.

Classe 1: Facilidades e dificuldades enfrentadas no desenvolvimento das atividades de educação ambiental e arboviroses no contexto escolar

Aponta-se que a classe 1 equivale a 19,4\% do corpus textual e está diretamente relacionada com as demais classes, quando se realiza uma leitura visual, tendo em vista ser responsável por dar origem às demais. Percebe-se, no entanto, quando se realiza uma leitura de conteúdo da mesma, que, apesar de abordar vocabulários semelhante às demais, é a única classe que se distancia dos aspectos textuais contidos nas outras, na medida em que aborda aspectos referentes às dificuldades e facilidades do processo educacional voltado para a educação ambiental e para as arboviroses. Elencam-se, nesse contexto, entraves e potencialidades que podem atrapalhar ou favorecer o processo de ensino-aprendizagem nesse público, além de contemplar aspectos referentes ao processo de capacitação pedagógica voltada para essa temática nas escolas em questão.

Levantou-se que os vocábulos mais frequentes e expressivos nesta classe foram: facilidade; fragilidade; não; específico; já; conseguir; conhecido; muito; acesso; aluno; material; participar; envolver; temática; informação; grande; diferente; conscientizar; conhecimento; apoio; problema; professor e quando.

Ajuda-se, por meio de algumas falas dos professores, a compreender, de forma ilustrativa, o conteúdo da classe.

[...] não participei de capacitação sobre essa temática; já participei com outra temática, a facilidade é o acesso à informação, à internet e dificuldade é conseguir a interação do aluno. (Professor 10, escore: 271.42)

[...] uma facilidade é a temática ser muito conhecida; já a dificuldade é conseguir o engajamento do aluno. (Professor 16, escore: 295.32) 
[...] facilidade é um tema abrangente que encontra muita coisa na internet abordando o assunto e que é de fácil acesso. Quanto à dificuldade, é a resistência por parte de algumas pessoas porque, assim, quando sairmos em passeata tentando conscientizar as pessoas, nem todas são receptivas. (Professor13, escore: 186.91)

[...] não específico para a dengue, já vieram falar do barbeiro e a Doença de Chagas. (Professor 21, escore: 277.67$)$

Percebe-se, pela leitura das falas, que uma das facilidades em abordar essas temáticas no contexto escolar, conforme os professores, consiste no fato de os mesmos a considerarem conhecida e de fácil acesso à informação, o que pressupõe que os alunos já tinham algum conhecimento sobre a mesma quando indagados sobre o assunto.

Descreve-se, no que se refere às dificuldades, que a maioria dos professores considerou ter dificuldade em conseguir a participação, engajamento e interação do aluno. Revela-se, quanto às palavras "não" e "específica”, citadas nessa classe, que elas dizem respeito à ausência de capacitação específica para os professores trabalharem arboviroses nas escolas, o que também prejudica o desenvolvimento dessas atividades nesse ambiente.

\section{Classe 2: Caracterização do desenvolvimento das atividades de arboviroses no contexto escolar}

Equivale-se a classe 2 a 19,4\% do corpus textual. Relaciona-se esta classe diretamente à classe 5, e os vocábulos mais frequentes e expressivos destes segmentos de texto foram: cartaz; culminância; paródia; apresentar; dia; apresentação; projeto; organizar; peça; mosquito; panfleto; confeccionamos; sala; vídeo; ficar; texto; leitura; dar; ralação; palestra; trazer; mandar; também; internet; as arboviroses e retirar.

Apresentam-se, nesta classe, as principais estratégias utilizadas pelos professores e pela gestão escolar para o desenvolvimento de atividades relacionadas às arboviroses nas escolas. Observa-se que estas estratégias buscam abranger os discentes e a comunidade, favorecendo, assim, o envolvimento do discente no processo de construção do conhecimento relacionado à temática e gerando impacto social positivo. Ajuda-se a compreender melhor essas atividades por algumas falas dos professores.

[...] esse ano, houve a culminância de um projeto; aí, nesse dia, todas as salas apresentaram os trabalhos que haviam produzidos tipo paródias, cartazes, a peça, eu e um aluno nos vestimos do mosquito. (Professor 6, escore: 243.15) 
[...] usei muitos vídeos que pegava na internet, os vídeos mostravam o ciclo de vida do mosquito, os focos, videoaula sobre dengue. Passei atividades, confeccionamos mosquitos de papéis, fizemos também paródias, apresentamos na escola, foi feito peças que eles mesmos procuraram e encenaram. Teve palestra no mês de março, foi em relação ao meio ambiente, foi pontual. (Professor 6, escore: 118.74)

[...] geralmente, fazemos a sensibilização em sala de aula, saímos ecampo com teor informativo, distribuição de cartazes, folhetos informativos para a população. Aqui, na escola, temos o projeto: Dengue aqui não, um simples gesto pode salvar! Então, seguimos o que tem nele. (Professor 10, escore: 88.00)

Verifica-se, diante das falas, que as escolas em estudo abordam essa temática de diversas formas, utilizando-se, para isso, de metodologias capazes de envolver os discentes como paródias, peças teatrais, leitura de textos, vídeos e cartazes, sendo estas estratégias usadas em todas as escolas em estudo. Acrescenta-se, entretanto, que algumas outras estratégias igualmente importantes e eficazes, como passeatas, confecção de mosquitos, produção de desenhos e informativos em rádios, apenas uma escola realizava.

\section{Classe 3: Planejamento das atividades de arboviroses no contexto escolar}

Informa-se que a classe 3 equivale a $23,1 \%$ do corpus textual. Relaciona-se esta classe diretamente com as classes 4 , e os vocábulos mais frequentes e expressivos destes segmentos de texto foram: área; chikungunya; junto; dengue; reunir; zika; sentar; gestão; planejar; sala; mais; depois; professor; assunto; ciência; passado; então; ano; acordo; desenvolvido; multimeios; abordar; aqui e desenvolver.

Apresenta-se, nesta classe, como ocorre o planejamento das atividades voltadas para as arboviroses nas escolas, onde existe uma articulação com os diversos atores do processo educacional, o que se caracteriza como essencial, tendo em vista que possibilita uma troca de informações favoráveis ao desenvolvimento eficaz da aprendizagem.

[...] de início, a gestão da escola nos procurou (professores da sala de multimeios) para planejamos quais os temas mais relevantes para se trabalhar no decorrer do ano; a dengue, zika e chikungunya foram elencadas devidos aos inúmeros casos que ocorreram ano passado aqui na cidade e no Brasil. (Professor 09, escore: 82.66)

[...] como já temos o projeto chamado "Dengue aqui não, um simples gesto pode salvar" arquivado, no início do ano, nós, da sala de multimeio, junto com a gestão escolar e alguns 
professores, sentamos e discutimos a respeito do mês que vamos desenvolver essa temática.

(Professor 11, escore: 69.28)

[...] então, seguimos o que tem nele de início, se reunimos com a sala de multimeios, gestão escolar e professores para planejarmos juntos e depois cada professor planeja junto dos alunos porque é necessário que eles se envolvam. (Professor 10, escore: 80.99)

Percebe-se, diante do exposto, que o planejamento é feito por meio da gestão escolar, dos professores da sala de multimeios, leitura ou professores de disciplinas como Ciência, Arte e Formação Cidadã. Torna-se a organização das atividades nas escolas bastante semelhante: a princípio, a temática é trabalhada em sala de aula; posteriormente, ocorre a construção de materiais sobre a temática e, por fim, é escolhido um dia para a culminância do projeto, onde todos os alunos e professores se reúnem e apresentam o que foi elaborado em sala sobre a temática.

Ressalta-se que apenas uma escola tem um projeto já definido denominado: “Dengue aqui não, um simples gesto pode salvar". Percebe-se, desse modo, que a arbovirose em destaque nessa escola é a dengue, o que acaba por limitar o conhecimento em relação às demais, mesmo figurando como uma iniciativa relevante, tendo em vista que um projeto imprime a ideia de continuidade.

Corroboram-se, por esses achados, estudos que enfatizam que, quando se verificam os principais responsáveis pelo planejamento e desenvolvimento de atividades relacionadas à educação ambiental e arboviroses, observa-se que tais funções, em sua maioria, são realizadas pela gestão escolar e pelos professores de Ciências e Geografia, com exceção do professor de Geografia que, neste estudo, não se destacou como responsável por ações relacionadas a essa temática. ${ }^{9-10}$

Evidenciou-se, pelos resultados do estudo, que a responsabilidade pelo desenvolvimento de práticas voltadas para a educação ambiental era de responsabilidade de professores da sala de multimeios e de disciplinas, a saber, Formação Cidadã e Arte.

Destaca-se, nesse prisma, o papel dos gestores como principal incentivador para o desenvolvimento de ações voltadas para a educação ambiental no ambiente escolar. Emerge-se, no entanto, a necessidade de disponibilização de materiais para que tais práticas possam ser executadas. ${ }^{11}$

\section{Classe 4: Parcerias envolvidas nas atividades de arboviroses no contexto escolar}

Expõe-se que a classe 4 equivale a $14,8 \%$ do corpus textual, e esta classe relaciona-se diretamente com a classe 3. Detalha-se que os vocábulos mais frequentes e expressivos destes segmentos de texto foram: saúde; secretaria; comunitário; agente; enfermeiro; ação; parceria; 
levar; oficina; educação; secretaria; planejamento; geralmente; como; social; endemia; reunião; vez; retirar; folheto; PSE; dar; vir; até; participar e internet.

Expressam-se, nesta categoria, as principais parcerias envolvidas nas atividades voltadas para as arboviroses, o que demonstra a importância de articulação e formação de parcerias com outros segmentos capazes de fornecer o suporte adequado na organização e desenvolvimento dessas atividades no contexto escolar.

[...] nessa escola, quando vamos trabalhar com esses temas, na maioria das vezes, temos o apoio da Secretaria de Saúde e Educação, ACSs, agentes de endemias, enfermeiro do PSE. (Professor 18, escore: 150.19)

[...] tivemos parceria com a Secretaria de Saúde e Educação do município. (Professor 02, escore: 112.90)

[...] tanto a Secretaria de Educação como a Secretaria de Saúde, todos os anos, incentivam a gente a proporcionar para eles algumas atividades sobre arboviroses. (Professor 03, escore: 104.11)

Pontua-se, conforme identificado nas falas, que todas as escolas em estudo possuem parceria com a Secretaria de Educação e de Saúde, porém, o apoio ofertado às mesmas configura-se como atividades pontuais, como entrega de panfletos e palestra com alunos e pais. Aponta-se, no que se refere à atuação do profissional de Enfermagem, pelos resultados, que ele não desenvolve ações de planejamento e execução de práticas educativas voltadas para a educação ambiental no ambiente escolar.

\section{Classe 5: Principais temáticas desenvolvidas sobre educação ambiental no contexto escolar}

Constata-se que a classe 5 equivale a $23,1 \%$ do corpus textuais, e esta classe relaciona-se diretamente com a classe 2 . Acrescenta-se que os vocábulos mais frequentes e expressivos destes segmentos de texto foram: ambiente; meio; preservação; lixo; limpo; ambiental; relacionado; semana; manter; gincana; livro; jogar; cuidado; escolar; por meio; comunidade; conversa; descarte; trabalhar; relação; falar; menino; importância; questão; ao; roda e parede.

Elencam-se, nesta classe, as principais temáticas abordadas pelos professores nas escolas sobre educação ambiental, sendo possível verificar que as atividades abordam, em especial, aspectos referentes à preservação do meio ambiente e ao lixo.

[...] trabalhamos a questão do meio ambiente em si, a questão da higiene com relação ao lixo, preservação do meio ambiente escolar, mantendo limpo; desenvolvemos projetos conscientizadores com as famílias, alunos e comunidade do geral. (Professor 05, escore: 227.55) 
[...] foi feito uma gincana com eles sobre preservação do meio ambiente escolar; eu saía em sala em sala ao final da aula para ver qual sala estava mais limpa; a que estivesse, ganhava uma quantidade de pontos. (Professor 8, escore: 179.79)

[...] as atividades de educação ambiental estão mais relacionadas com preservação do meio ambiente e lixo. (Professor 11, escore: 171.74)

Percebe-se, diante do exposto, que os principais conteúdos trabalhados nas escolas sobre educação ambiental foram: preservação do meio ambiente; preservação do patrimônio escolar; desmatamento e descarte adequado do lixo. Informa-se que as estratégias usadas para o desenvolvimento da temática em questão foram: leitura de textos nos livros; organização de gincanas sobre preservação da escola e competições entre salas na semana do meio ambiente.

Destaca-se que nenhum professor relacionou alguma atividade sobre arbovirose como conteúdo de educação ambiental, eles só falavam sobre arboviroses quando perguntados acerca da existência de atividade educativa sobre a temática.

\section{DISCUSSÃO}

Elucidam-se, nos resultados analisados, dificuldades relacionadas ao desenvolvimento de práticas educacionais que abordem a temática saúde ambiental, evidenciadas pela falta de planejamento. Torna-se relevante, desse modo, que o professor, durante o planejamento das atividades a serem desenvolvidas em sala de aula, passe a considerar o conhecimento prévio dos discentes, tendo em vista que essa temática, na maioria das vezes, também é abordada pela mídia, e isso pode constituir-se como fator facilitador para que o ocorra o envolvimento do aluno no processo educativo. ${ }^{12-3}$

Torna-se importante, no entanto, considerar que, apesar de ser um conteúdo bastante divulgado, sempre podem restar dúvidas referentes ao mesmo, dúvidas essas que colaboram para o comprometimento da saúde da população devido à maneira como as informações são transmitidas. ${ }^{7}$

Alerta-se, além disso, que saber quais são as principais dificuldades enfrentadas pelos educadores para o desenvolvimento do processo educacional é de extrema importância para melhorar a qualidade do ensino.

Aponta-se, pelos resultados obtidos, que as principais dificuldades enfrentadas pelos educadores para o desenvolvimento de práticas voltadas para saúde ambiental no contexto escolar estão relacionadas a questões orçamentárias, estrutura física das instituições, falta de recursos humanos e financeiros, capacitação e motivação para o desenvolvimento de projetos e dificuldade de interação dos discentes com a temática voltada para a promoção da saúde. 
Compreende-se a importância do desenvolvimento de práticas educacionais em saúde no contexto escolar como espaço para discussões e debates acerca de temas de saúde e meio ambiente como forma de sensibilizar o escolar quanto à prevenção e promoção de combate às arboviroses, possibilitando, assim, que esse discente se torne autônomo quanto ao seu processo saúde-doença. ${ }^{10}$

Observa-se que, apesar do acesso à informação se constituir como um aspecto facilitador deste estudo, ainda existem dificuldades a serem superadas para conseguir o envolvimento do aluno durante as atividades relacionadas às arboviroses.

Percebe-se, desse modo, que as escolas usam múltiplas estratégias educacionais para o desenvolvimento das suas atividades e essas diversas estratégias podem decorrer da busca para superar as dificuldades encontradas frente à realização do processo educativo sobre arboviroses, tentando envolver os alunos para que possam perceber sua importância diante da erradicação do mosquito causador dessas doenças.

Possibilita-se, aos educadores, pela utilização de metodologias ativas no espaço escolar, diversificar suas atividades por meio de ferramentas que instigam o aluno a refletir, propor soluções e construir uma visão crítica acerca de problemas sociais que o circundam. Infere-se, dessa forma, que o discente passe a ser um sujeito ativo quanto ao processo de ensinoaprendizagem e não um mero receptor de tudo que é transferido pelo docente. ${ }^{14-5}$

Sabe-se que tecnologias educativas, como paródias, vídeos, músicas, interações e conversas, são ferramentas satisfatórias para a disseminação de conhecimento e conscientização, pois proporcionam o desenvolvimento de senso crítico no aluno, que resulta na necessidade de encontrar soluções para resoluções dos problemas ambientais. ${ }^{14}$

Enfatiza-se, nesse contexto, o uso de vídeo educativo na sala de aula como uma ferramenta didático-pedagógica poderosa para fornecer informações aos alunos, pois possibilita um maior aprendizado de forma clara e objetiva, despertando, no aluno, o interesse pela temática que facilita a integração dos mesmos para discutir o assunto abordado. ${ }^{3}$ Ressalta-se, além disso, o uso de oficinas e peça teatral como ferramentas bastante eficientes na sensibilização dos alunos quanto a temas diversos, proporcionando uma aprendizagem significativa. ${ }^{13}$ Destaca-se, nessa direção, a utilização de jogos educativos como ferramentas bastante utilizadas para proporcionar conhecimento aos alunos por meio da participação dos mesmos no processo de ensinoaprendizagem. Observa-se, desse modo, que os jogos podem ser utilizados com o objetivo de 
superar algumas das fragilidades que esta pesquisa identificou, apesar da mesma não ter encontrado os jogos como ferramentas utilizadas pelos participantes do estudo. ${ }^{16}$

Identifica-se que as escolas participantes desta pesquisa trabalham as arboviroses por meio de estratégias que são consideradas satisfatórias para sensibilizar os alunos sobre a temática e, com isso, pode-se inferir que as mesmas já estão no caminho certo para superar as dificuldades encontradas no desenvolvimento de ações educativas que visam a conscientizar os alunos e, assim, a multiplicar conhecimentos com o objetivo de reduzir a proliferação do mosquito Aedes aegypti e prevenir as arboviroses.

Planejam-se as ações de saúde pelas Secretarias de Saúde e de Educação, podendo haver a possibilidade de a demanda vir da escola. Ocorre-se o planejamento a partir da identificação de prioridades relacionadas à saúde da comunidade educativa e da comunidade em geral, de acordo com as suas reais necessidade de saúde. ${ }^{17}$

Lembra-se, no entanto, para que ocorra a realização do planejamento e desenvolvimento de atividades educativas de forma efetiva, que se faz necessário que os responsáveis tenham conhecimento do tema abordado nas práticas para que não haja prejuízos no aprendizado dos discentes. ${ }^{18}$ Evidenciou-se, além disso, a ausência de capacitação específica para os educadores sobre o assunto.

Observa-se, embora existam disciplinas relacionadas com a temática em questão, a exemplo das Ciências, a falta de envolvimento por parte dos docentes e discentes na execução e planejamento de práticas que abordem a temática saúde ambiental no âmbito escolar.

Poder-se-ia proporcionar, por um maior envolvimento por parte desses atores, a integração com outras disciplinas, a exemplo da Ciências, destacando a importância de o discente compreender o seu papel no processo educacional de modo a superar as dificuldades elencadas pelos professores de conseguir o envolvimento dos estudantes nas atividades.

Elencam-se as parcerias envolvidas no processo educativo sobre educação ambiental e arboviroses responsáveis pelo planejamento dessas atividades: Secretaria Municipal de Educação; gestão escolar e grupo de professores específicos. ${ }^{10-1}$

Destaca-se, nesse prisma, a intersetorialidade no processo de prevenção das arboviroses, considerando-a como uma estratégia potencializadora no intuito de incentivar a participação da comunidade escolar na prevenção de doenças. Vem-se o desenvolvimento de ações de educação em saúde ao encontro da ruptura do modelo biomédico ainda presente na assistência ofertada pelos profissionais de saúde. ${ }^{19-20}$ 
Pode-se a educação em saúde ser um método eficaz para a disseminação do conhecimento, visto que a escola é um ambiente propício para expandir informações por meio de alunos, pais e comunidade. ${ }^{7}$

Destaca-se o enfermeiro, no ambiente escolar, diante dos profissionais da saúde, pois ele é responsável por diagnosticar os problemas mais relevantes nesse ambiente e, assim, desenvolver ações que visem à resolução de problemáticas por meio de práticas de educação em saúde a partir da necessidade da comunidade porque é o profissional capacitado para promover o desenvolvimento de estratégias de ensino e saúde que possibilitem mudanças comportamentais em uma comunidade..$^{21}$

Discorreu-se, em estudo sobre a execução de um projeto de intervenção de educação em saúde para o controle da dengue com alunos de uma escola, sobre a importância do papel do profissional de Enfermagem da atenção básica de saúde como o principal responsável pelo desenvolvimento de prática de educação em saúde. Torna-se a intersetorialidade entre saúde e educação uma estratégia eficiente e eficaz para práticas promotoras de saúde..$^{22}$

Observa-se, nos resultados, no entanto, que a participação do profissional de Enfermagem ocorre de maneira distante no desenvolvimento de ações relacionadas a arboviroses, visto que o mesmo não é incluído no planejamento e/ou desenvolvimento de nenhuma atividade educativa que abordasse a temática em questão no contexto escolar. Referiu-se, apenas, à presença do enfermeiro no dia da culminância do projeto de uma escola e passeata, sendo citado como parceiro da escola em outros momentos, tais como participação no PSE por meio do desenvolvimento de atividades educativas sobre outros assuntos.

Trata-se, assim, a educação ambiental de uma prática cotidiana realizada nas escolas que possui alguns temas que são mais discutidos em sala de aula. Destacam-se, dentre eles, o descarte adequado de lixo, a contaminação do solo e da água; agrotóxicos e alimentação; solo e seus componentes; poluição do ar, da água e do solo, dando ênfase à agua. ${ }^{10,23}$ Percebe-se, desse modo, que o descarte adequado de lixo também foi evidenciado em outras literaturas, corroborando os achados deste estudo.

Apontam-se, pelas atividades de educação ambiental nas escolas, o desmatamento, o aquecimento global e a ecologia como os principais assuntos trabalhados no ambiente escolar, com temas voltados para o lixo, reciclagem e preservação como os assuntos abordados sobre educação ambiental na escola. ${ }^{24}$ Sinaliza-se, pelo desenvolvimento de práticas educacionais com ênfase à 
saúde ambiental, para a necessidade da criação de ambientes saudáveis, melhorando a condição de saúde dos escolares. ${ }^{25-6}$

Enfatiza-se, nesse contexto, a importância da gestão de resíduos como uma relevante medida para o controle dos inúmeros casos de arboviroses, conseguindo relacionar a educação ambiental e o descarte inadequado do lixo com a incidência das arboviroses, e isso vai além do que os participantes deste estudo conseguiram relacionar. ${ }^{11}$

Torna-se evidente, assim, que os participantes deste estudo não conseguiram relacionar a temática educação ambiental com arboviroses, e percebe-se que os mesmos fazem uma distinção dos assuntos de maneira que essa é uma temática articulada apenas em atividades relacionadas à saúde. Pode-se refletir, desse modo, que estas escolas em estudo não conseguem articular a relação de interdependência entre ambiente e saúde quanto à proliferação do Aedes aegypti e às arboviroses por ele transmitidas.

\section{CONCLUSÃO}

Evidenciou-se, pelo estudo, ao buscar analisar as práticas pedagógicas voltadas à educação ambiental com a temática das arboviroses no contexto escolar, que o tema educação ambiental se caracteriza como essencial diante das inúmeras transformações ocorridas em escala global nas últimas décadas, devendo esse ser inserido no currículo.

Verificam-se, no entanto, algumas dificuldades vivenciadas no processo educacional no que se refere à educação ambiental e às arboviroses, a saber: falta de capacitação dos docentes associada e falta de interesse por parte dos alunos pela temática que se constitui como uma barreira para o desenvolvimento de práticas educacionais relacionadas à saúde ambiental.

Observou-se que a utilização de metodologias ativas proporciona uma maior participação e interação do discente quanto ao processo de ensino-aprendizagem, possibilitando que os mesmos desenvolvam maior autonomia e compreensão de temas relacionados à saúde e meio ambiente.

Ressalta-se, por fim, a necessidade da inserção de uma equipe multidisciplinar no cenário escolar, com atividades educativas e assistenciais sobre arboviroses, visto que os mesmos têm um papel importante para contribuir no fortalecimento da relação entre a saúde e a escola, desenvolvendo atividades educativas com a comunidade escolar.

\section{AGRADECIMENTOS}

À Coordenação de Aperfeiçoamento de Pessoal de Nível Superior (CAPES) pela concessão de bolsa de estudos à Sabrina Alaide Amorim Alves. 


\section{REFERÊNCIAS}

1. Ministério da Saúde (BR), Secretaria de Vigilância em Saúde, Departamento de Vigilância das Doenças Transmissíveis. Dengue: diagnóstico e manejo clínico: adulto e criança [Internet]. Brasília: Ministério da Saúde; 2016 [cited 2019 Dec 28]. Available From: https://www.saude.gov.br/images/pdf/2016/janeiro/14/dengue-manejo-adulto-crianca-5d.pdf 2. Ministério da Saúde (BR), Secretaria de Vigilância em Saúde. Monitoramento dos casos de dengue, febre de chikungunya e febre pelo vírus Zika até a Semana Epidemiológica 51 [Internet]. Brasília: Ministério da Saúde; 2017 [cited 2019 Aug 10]. Disponível em http: / / portalarquivos2.saude.gov.br/images/pdf/2018/janeiro/23/Boletim-2017-051-Dengue.pdf

3. Santos MEM, Batista WS, Oliveira JVF, Jansen ICC, Santos KFS, Santos ECR. Educational actions for fighting the mosquito aedes aegypti in a school in the metropolitan region of São Luís. Cad Pedagógico. 2017; 14(1):8-27. DOI: 10.22410/issn.1983-0882.v14i1a2017.1317

4. Wang L, Zhao H, Oliva SM, Zhu H. Modeling the transmission and control of Zika in Brazil. Sci Reports [Internet]. 2017 Aug [cited 2018 Aug 15]; 7:7721. Available from: https://www.nature.com/articles/s41598-017- 07264-y

5. Ministério do Meio Ambiente (BR), Diretoria de Educação Ambiental, Ministério da Educação (BR), Coordenação Geral de Educação Ambiental. Programa nacional de educação ambiental [Internet]. Brasília: Ministério do Meio Ambiente; 2005 [cited 2019 Dec 12].Available from: https://www.mma.gov.br/estruturas/educamb/_arquivos/pronea3.pdf

6. Arruda LP, Moreira ACA, Aragão ALA. Promoção da saúde: atribuições do enfermeiro como educador na estratégia saúde da família. Essentia [Internet]. 2014 June/Nov [cited 2019 Aug 10]; 16(1):183-203. Available from: http://essentia.uvanet.br/index.php/ESSENTIA/article/view/10

7. Santos MM, Silva FC, Muller JM. The assimilation of information passed by campaigns about aedes aegypti and your arboviruses circulation in Brazil by children of the elementary school. Rev Inova Ciênc Tecnol [Internet]. 2018 Jan/June [cited 2019 Aug 10]; 4(1):49-52. Available from: http://periodicos.iftm.edu.br/index.php/inova/article/view/231 
8. Camargo BV, Justo AM. IRAMUTEQ: interface de R pour les analyses multidimensionnelles de textes et de questionnaires. Temas Psicol. 2013 Dec; 21(2):513-8. DOI: 10.9788/TP2013.2-16

9. Araújo DHS. A importância da experimentação do ensino de Biologia. 2011 [dissertation] [Internet]. Brasília: Universidade de Brasília; 2011 [cited 2019 Aug 10]. Available from: https://bdm.unb.br/bitstream/10483/1925/1/2011_DayaneHolandadeSouza.pdf

10. Monteiro IFC, Monteiro PDEBSC. O. A educação ambiental e as representações sociais dos professores da rede pública no ensino fundamental. RevBEA. 12(1):165-76. DOI: 10.34024/revbea.2017.v12.2391

11. Alecrim JS, Cotta A, Castro JM. Relationship between the actions for the dengue fever prevention and the impact caused on the cases reported between 2009 and 2010. J Health Sci [Internet]. 2016 Sept/Dec [cited 2018 Aug 15]; 18(4):286-90. Available from: https://revista.pgsskroton.com/index.php/JHealt hSci/article/view/3834/0

12. Santos KKS, Barros SMS. Percepção sobre educação em saúde e ambiental de mosquitos vetores entre escolares [dissertation] [Internet]. Maceió: CESMAC; 2017 [cited 2019 Dec 28]. Available from: https: //ri.cesmac.edu.br/handle/tede/234

13. Cruz MRP. Oficina sobre as arboviroses no ensino médio: o teatro como uma ferramenta Pedagógica. Rev Vivências [Internet]. 2017 [cited 2019 Aug 10], 1(1):13945. Available from: https: / / periodicos.ufpe.br/revistas/vivencias/article/view/238890/0

14. Sousa GS, Machado PB, Reis VR, Santos AS, Dias AB. Educação ambiental como ferramenta para o manejo de resíduos sólidos no cotidiano escolar. RevBEA. 2013 Feb; 8(2):118-30. DOI: 10.34024/revbea.2013.v8.1792

15. Freire P. Pedagogia do oprimido. 48th ed. Rio de Janeiro: Paz e Terra; 2005.

16. Gurgel SS, Taveira GP, Matias EO, Pinheiro PNC, Vieira NFC, Lima FET. Educational games: didactic resources utilized at teaching health education classes. REME Rev Min Enferm. 2017 Nov; 21:e-1016. DOI: $10.5935 / 1415-2762.20170026$

17. Vieira DS, Dias IKR, Sobreira CLS, Brito Junior FE, Lopes MSV. Coping with Aedes aegypti in the brazilian context. J Nurs UFPE on line. 2019;13:e241722 DOI: 10.5205/1981-8963.2019.241722

18. Becker RA, Hüller CR, Silva BA. Abordagem da educação ambiental na escola municipal Carlos Lacerda [dissertation] [Internet]. Medianeira: UTFPR; 2011 [cited 2019 Aug 10]. Available from: http: //repositorio.roca.utfpr.edu.br/jspui/handle/1/466 
19. Flisch TMP, Evangelista JG, Pimenta DN. The perceptions of health managers about intersectoriality: integrating health and education in the context of dengue. Rev Bras Pesq Saúde. 2018 Apr; 19(3):109-17. DOI: 10.21722/rbps.v19i3.21091

20. Lima AWS, Mongiovi VG, Marinus MWLC, Lima LS. Health education in or with the school? J Nurs UFPE on line. 2018 June; 12(6):1790-9. DOI: 10.5205/1981-8963-v12i6a236475p1790-1799-2018

21. Costa GM, Figueredo RC, Ribeiro MS. A importância do enfermeiro junto ao PSE nas ações de educação em saúde em uma escola municipal de GURUPI. Rev Cient ITPAC [Internet]. 2013 Apr [cited 2019 Aug 610]; 6(2):01-12. AVailable from:

\section{https://assets.unitpac.com.br/arquivos/Revista/62/6.pdf}

22. Fernandes PS. Jovens multiplicadores de informações: projeto de intervenção de educação em saúde para o controle da dengue com alunos de uma escola municipal [Internet][dissertation]. Belo Horizonte: Universidade Federal de Minas Gerais; 2015 [cited 2019 Aug 10]. Available from: https://www.nescon.medicina.ufmg.br/biblioteca/imagem/5003.pdf

23. Giassi MG, Dajori JF, Machado AC, Martins MC. Environment and citizenship: environmental education in Schools. Rev Extensão. 2016; 1(1):1-9. DOI: 10.18616/re.v1i1.2461

24. Gasques ACF, Okawa CMP, Santos JD, Gasques EGF, Delabio F. Educação ambiental: estudo de caso em dois colégios estaduais da cidade de Sarandi (PR). RevBEA [Internet]. 2016 [cited 2019 Aug 10]; 11(5):123-38. Available from: http://revbea.emnuvens.com.br/revbea/article/view/4984

25. Jung EM, Jagals P, Brereton C, Sly PD, Kim R, Kim EM, Há EH. Children's Environmental Health Indicators in Context of the Sustainable Development Goals for Small Island Developing States. Int J Environ Res Saúde Pública. 2018 July; 15(7):1404. Doi: 10.3390 / ijerph15071404

26. Neira M, Fletcher E, Brune-Drisse MN, Pfeiffer M, Adair-Rohani H, Dora C. Environmental health policies for women's, children's and adolescents' health. Bull World Health Organ. 2017 Feb/July; 95:604. DOI: 10.2471 / BLT.16.171736

\section{Correspondência}

Sabrina Alaide Amorim Alves

E-mail: sabrina1995amorim@gmail.com

Submissão: $26 / 03 / 2020$

Aceito: $25 / 01 / 2021$

Copyright $\odot 2021$ Revista de Enfermagem UFPE on line/REUOL.

(cc) EY Este é um artigo de acesso aberto distribuído sob a Atribuição CC BY 4.0 Creative Commons AttributionShareAlike 4.0 International License, a qual permite que outros distribuam, remixem, adaptem e criem a partir do seu trabalho, mesmo para fins comerciais, desde que the atribuam o devido crédito pela criação original. É recomendada para maximizar a disseminação e uso dos materiais licenciados. 